\title{
The Vibration Analysis of the Cracked Shaft
}

\author{
Zhen-Bo XIE ${ }^{1, a^{*}}$, Hong-Wei LI, ${ }^{1, b}$ and Jing XIE ${ }^{1, c}$ \\ ${ }^{1}$ Qingdao, Shandong, China Si liu Road No. 2 \\ asymbol2008@163.com \\ Corresponding author
}

Keywords: Cracked Shaft, Numerical Analysis, Vibration Analysis.

\begin{abstract}
In this paper, the numerical method is used to analyze the effect of the crack on the vibration of shaft. Firstly, with Patran/Nastran calculate and compare the free shaft mode and the crack shaft mode. Then numerically calculate the natural frequencies and modes of the shaft at different length and crack depth and crack location. Analyze the effect of crack on shaft vibration.
\end{abstract}

\section{Introduction}

In the rotor system, the crack shaft fault is a serious consequence. It's difficult to diagnose, also a sudden failure. Especially the rotor is an important part of the system. The broken shaft accident caused by crack is often a great disaster ${ }^{[1]}$.

The commonly method to detect the rotor failure is to detect the fault of the cracked rotor by the vibration response of the rotating shaft. This requires a deeper understanding of the vibration response induced by the crack. The key is to establish a reasonable and effective mathematical model of the cracked rotor. This paper studies the effects of crack on the shaft vibration ${ }^{[2]}$.

\section{Analysis of Crack Shaft}

\section{Differential Equation of Vibration}

The rotating machinery can be simplified into a multi disc support system. The system can be easily set up by the finite element method or the transfer matrix method [3]. The Differential equation of vibration is

$$
M \ddot{u}+(C+G) \dot{u}+K(t) u=P_{g}+P_{u}
$$

This paper only discusses the differential equation of Jeffcott rotor vibration and its solution process. When the system is cracked Jeffcott rotor, all of the squares is $2 \times 2$ matrix, all of the array is $2 \times 1$ array. When the rotor is supported by two characteristics of the same bearing, the gyro effect matrix of vibration differential equation is zero. Other matrices are

$$
\begin{aligned}
& M=\left[\begin{array}{cccc}
m & 0 & 0 & 0 \\
0 & m & 0 & 0 \\
0 & 0 & m_{b} & 0 \\
0 & 0 & 0 & m_{b}
\end{array}\right] \quad C=\left[\begin{array}{cccc}
c & 0 & 0 & 0 \\
0 & c & 0 & 0 \\
0 & 0 & c_{b x} & c_{b x y} \\
0 & 0 & c_{b x y} & c_{b y}
\end{array}\right] \quad u=\left\{\begin{array}{c}
x \\
y \\
x_{b} \\
y_{b}
\end{array}\right\} \\
& P_{g}=\left\{\begin{array}{c}
-m g \\
0 \\
0 \\
0
\end{array}\right\} \quad P_{u}=\left\{\begin{array}{c}
m e \omega^{2} \cos (\omega t+\varphi) \\
m e \omega^{2} \sin (\omega t+\varphi) \\
0 \\
0
\end{array}\right\} \quad K=\left[\begin{array}{cccc}
k_{x}(t) & k_{x y}(t) & -k_{x}(t) & -k_{x y}(t) \\
k_{x y}(t) & k_{y}(t) & -k_{x y}(t) & -k_{y}(t) \\
-k_{x}(t) & -k_{x y}(t) & k_{x}(t)+k_{b x(t)} & k_{b x y}(t) \\
-k_{x y}(t) & -k_{y}(t) & k_{b x y}(t) & k_{y}(t)+k_{b y(t)}
\end{array}\right]
\end{aligned}
$$

Where: $\mathrm{x}, \mathrm{y}, \mathrm{xb}$ and $\mathrm{yb}$ are the displacement of the rigid thin disc and bearing. $\mathrm{m}$ is the quality of rigid thin disks. $\mathrm{mb}$ is the bearing vibration quality. e and $\varphi$ are the phase angle of the eccentric distance and the rotational unbalance force of the rigid thin disc. $\mathrm{c}$ is the linear viscous damping 
coefficient. $\mathrm{Kx}(\mathrm{t}), \mathrm{ky}(\mathrm{t})$ and $\mathrm{kxy}(\mathrm{t})$ are coupling stiffness in the $\mathrm{X}$ direction, $\mathrm{Y}$ direction and the $\mathrm{XY}$ direction. cbx, cby, cbxy, kbx, kby and kbxy are the damping coefficient and stiffness coefficient of bearing. $\omega$ is the angular velocity of rotor rotation.

\section{Solution of Differential Equation of Vibration}

The solution process of the Jeffcott rotor vibration differential equation with an open crack and, is the same as the non cracked rotor of the cross. See the literature ${ }^{[4,5]}$.

For a good dynamic equilibrium and horizontal crack rotor, the opening and closing of the crack is controlled by the gravity. For an elastic support single disc rotor with gravity control for opening and closing crack, time varying stiffness are

$$
\begin{aligned}
& k_{x}=k_{0}-\Delta k_{x}\left(1-\Delta k_{x}^{\prime}\right) / 2 \\
& k_{y}=k_{0}-\Delta k_{y}\left(1-\Delta k_{y}^{\prime}\right) / 2 \\
& k_{x y}=\Delta k_{x y} \Delta k_{x y}^{\prime} / 2 \\
& \qquad \Delta k_{x}^{\prime}=\sum_{n=0}^{5} a_{x n} \cos (n \omega t) \quad \Delta k_{y}^{\prime}=\sum_{n=0}^{5} a_{y n} \cos (n \omega t) \quad \Delta k_{x y}^{\prime}=\sum_{n=0}^{5} b_{x y n} \sin (n \omega t) \\
& \text { Where: }
\end{aligned}
$$

The equations of first 5 harmonic component can be obtained with elastic support single shaft, under the excitation of gravity and rotational unbalance.

\section{Numerical Analysis of Crack Shaft}

It's a need to solve the differential equation of vibration for analyzing the vibration of the crack shaft. When many freedom degrees in the system, the solving process will have to inverse large matrix, and the calculation results can not directly reflect the influence of crack on the vibration. So far, widely use numerical analysis method to analyze the vibration of crack shaft along with the rapid development of computer technology.

\section{Modal Analysis of Single Crack Shalt}

Use Pro/E software to make full optical axis and the relative crack depth of 0.5 axis solid model. Then divide mesh and establish grid finite element model by Patran (Fig. 1 and Fig.2). Calculate modes of two axis structure with Nastran.
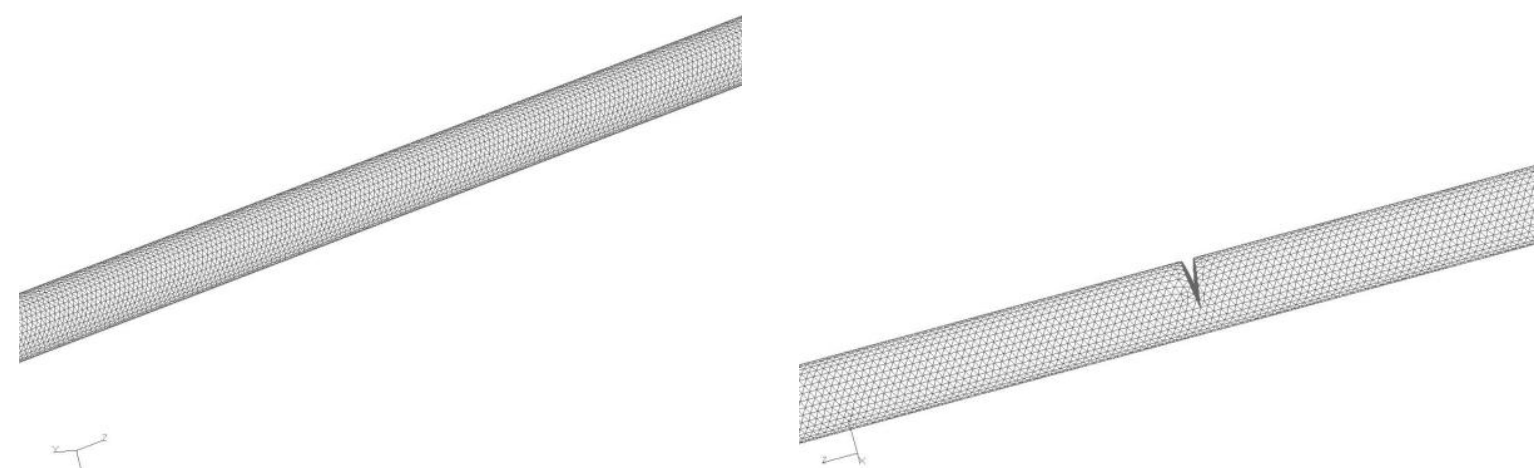

Fig.1 Finite element model of no cracked shaft

Fig.2 Finite element model of cracked shaft

(1) Computational model

The geometrical dimension of the optical axis is: the length of the rotating shaft $\mathrm{L}=0.3 \mathrm{~m}$, the diameter of $10 \mathrm{~mm}$, the crack shaft crack distance endpoint is $135 \mathrm{~mm}$, the crack depth is $5 \mathrm{~mm}$. 
Based on MSC/PATRAN2005 model, with the ten node tetrahedral elements, it's divided into 2155 elements. The number of nodes is 4092.

(2) Basic assumptions

In the finite element calculation process, the hypothesis is:

(a) The rotating shaft is a homogeneous, continuous, isotropic linear material.

(b) The Poisson ratio of the rotating shaft is constant.

(c) Rotating shaft inner boundary fixed.

(3) Load condition

Both ends of the rotating shaft are simply connected.

Material mechanical properties: Young's modulus $E=2.07 \times 10^{11} \mathrm{~N} / \mathrm{m}^{2}$, Poisson's ratio $v=0.3$, material density $\rho=7.8 \times 10^{3} \mathrm{~kg} / \mathrm{m}^{3}$.

(4) Calculation result

The first 2 order natural frequencies and modes of both axes can be obtained by Natran. See Table 1. The modal moire and deformation see Fig.3 and Fig.4.

Tab. 1 Numerical calculation of natural frequency of rotating shaft

\begin{tabular}{c|c|c}
\hline & $\begin{array}{c}\text { Natural frequency of no } \\
\text { crack shaft [Hz] }\end{array}$ & $\begin{array}{c}\text { Natural frequency of crack } \\
\text { shaft [Hz] }\end{array}$ \\
\hline First order (X plane bending) & 500.32 & 481.18 \\
\hline First order (Y plane bending) & 500.36 & 496.77 \\
\hline Second order (X plane bending) & 1369.5 & 1358.7 \\
\hline Second order (Y plane bending) & 1369.6 & 1366.8 \\
\hline
\end{tabular}

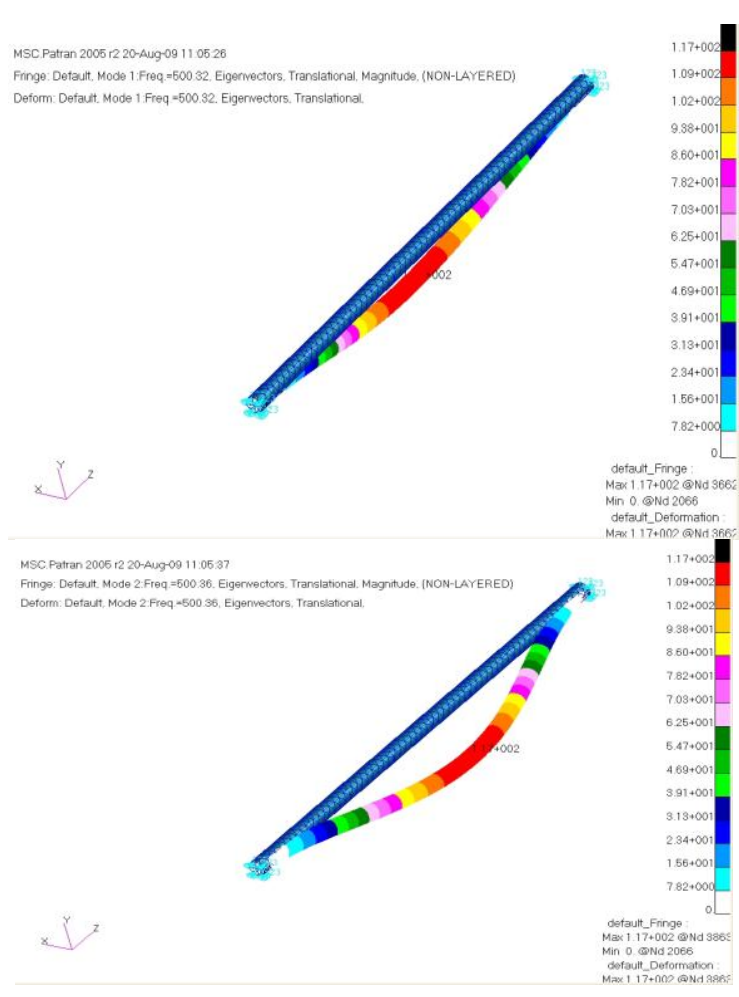

(a) No cracked shaft

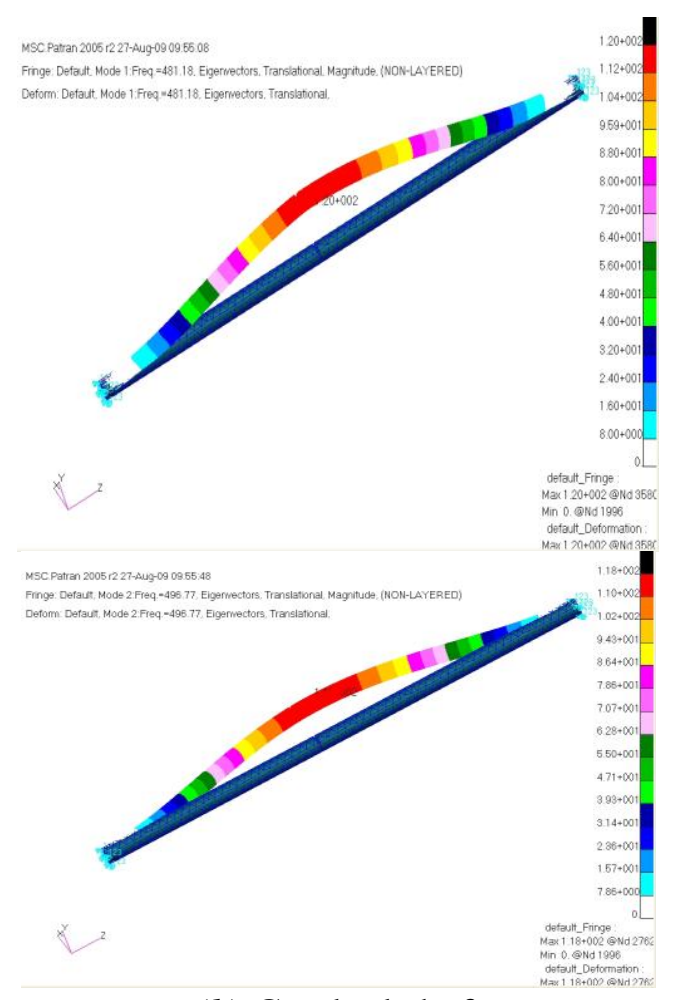

(b) Cracked shaft

Fig.3 First order modal moire and deformation 


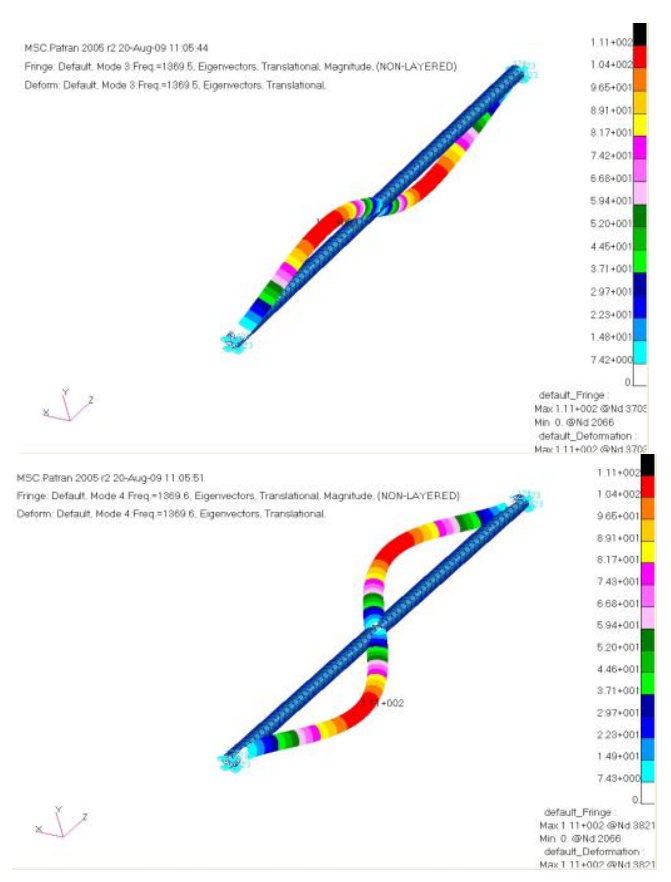

(a) No cracked shaft

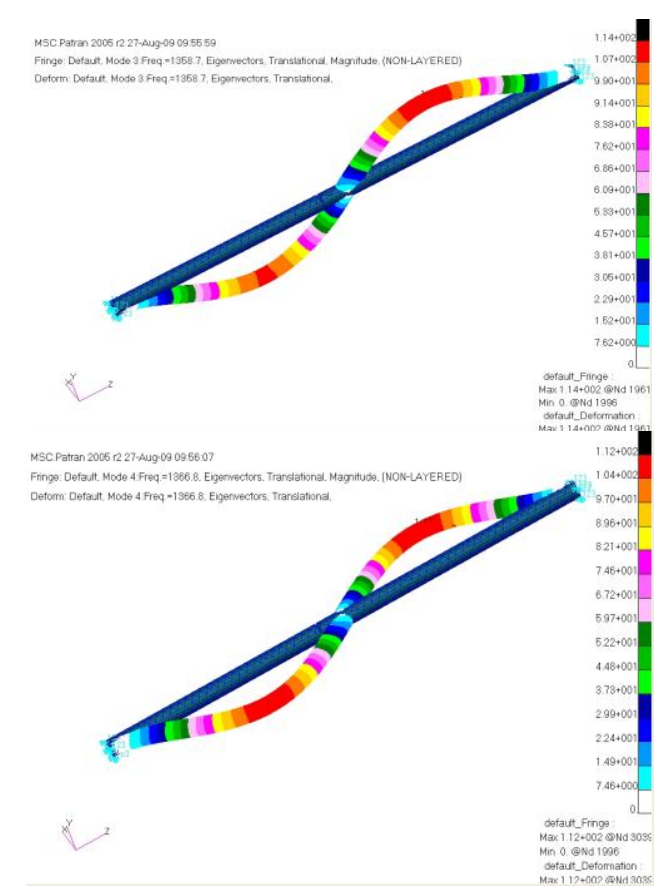

(b) Cracked shaft

Fig. 4 Second order modal moire and deformation

From the calculated results, at the crack point, the vibration due to the crack breathing effect increases the amplitude. Although the overall vibration mode cannot be changed, local vibration type (displacement) has a certain effect.

From table 1, it is found that the natural frequency of the rotating shaft is increased by ten $\mathrm{Hz}$ to tens $\mathrm{Hz}$ because the crack. In theory, the change of frequency can be measured in the experiment, which can detect the existence of the crack.

\section{Vibration Analysis of Double Crack Shaft}

\section{Effect of Slender Ratio}

Both cracks are assumed to be located in the different elements of the rotating shaft (the crack shaft is discretized into 10 beam elements). Crack locations are $\mathrm{Z} 1 / \mathrm{L}=0.45, \mathrm{Z} 2 / \mathrm{L}=0.75$. The relative crack depth are $\bar{a}_{d 1}=a_{d 1} / R=0.5, \bar{a}_{d 2}=a_{d 2} / R=0.5$. The characteristic frequencies $\omega c \mathrm{i}(\mathrm{i}=1,2,3)$ of the cracked shaft under different D / L ratios are obtained by the simplified finite element method of transfer matrix analysis and the local flexibility. See Table 2. First and second order modes of the cracked shaft with different slender ratios see Fig.5 and Fig.6 ( $\mathrm{z}$ is axial distance). Compared with the mode of no crack shaft, first order and second order modes at the crack location $\mathrm{Z} 1 / \mathrm{L}=0.45$ and Z2 $/ L=0.75$ have be changed. So the corresponding crack location can be identified by means of the vibration mode. Comparing Fig.5 with Fig.6, it's found that the mode change of crack shaft which less slender ratio is larger than another.

Tab. 2 Effect of slender ratio on the characteristic frequency of cracked shaft

\begin{tabular}{|c|c|c|c|c|c|}
\hline & $L / D=4$ & $L / D=6$ & $L / D=8$ & $L / D=10$ & $L / D=12$ \\
\hline$\omega_{c 1} / \omega_{n 1}$ & 0.9091 & 0.9368 & 0.9515 & 0.9607 & 0.9669 \\
\hline$\omega_{c 2} / \omega_{n 2}$ & 0.9280 & 0.9517 & 0.9636 & 0.9707 & 0.9755 \\
\hline$\omega_{c 3} / \omega_{n 3}$ & 0.9251 & 0.9490 & 0.9610 & 0.9684 & 0.9733 \\
\hline
\end{tabular}



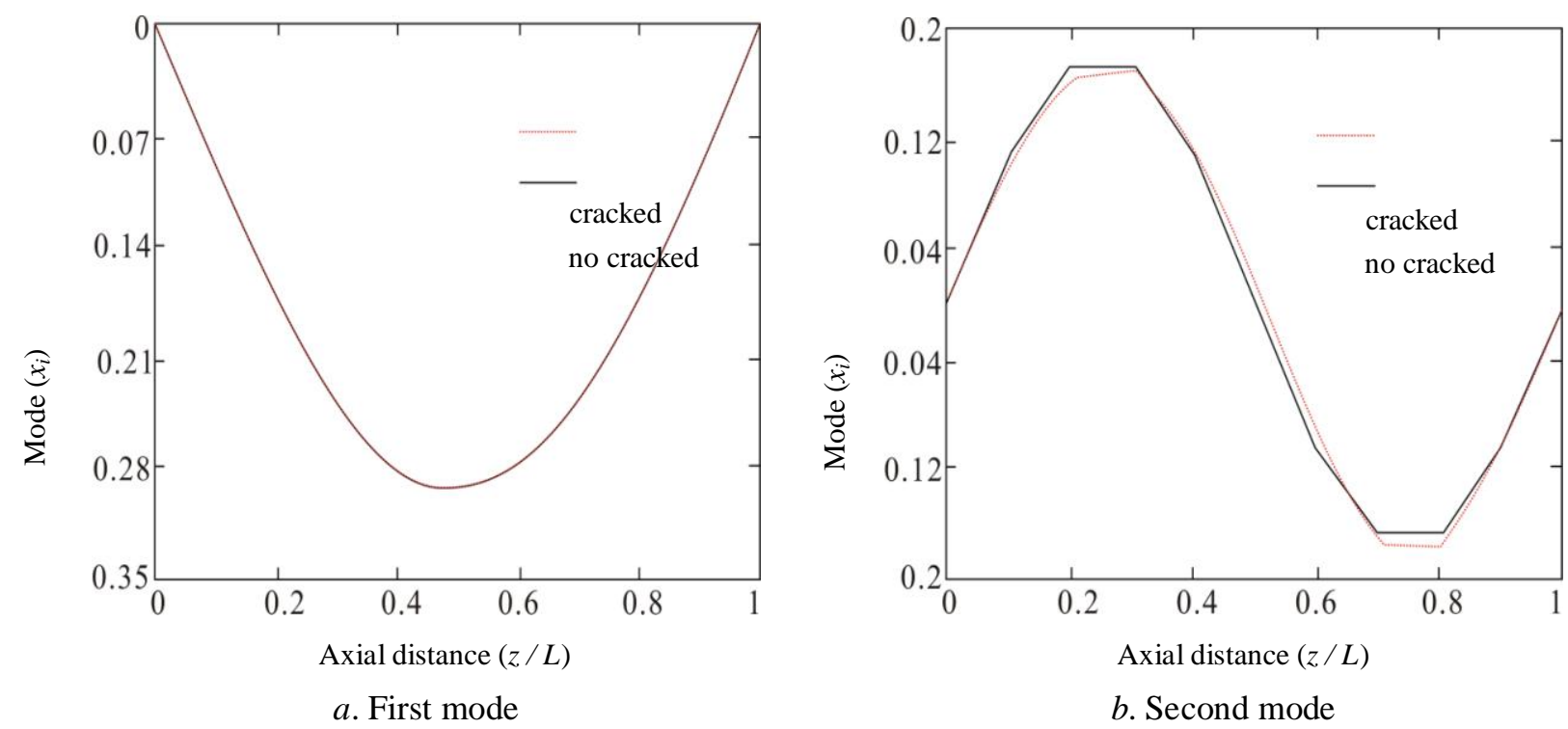

Fig.5 Modes of cracked and no cracked shafts $(\mathrm{L} / \mathrm{D}=4)$
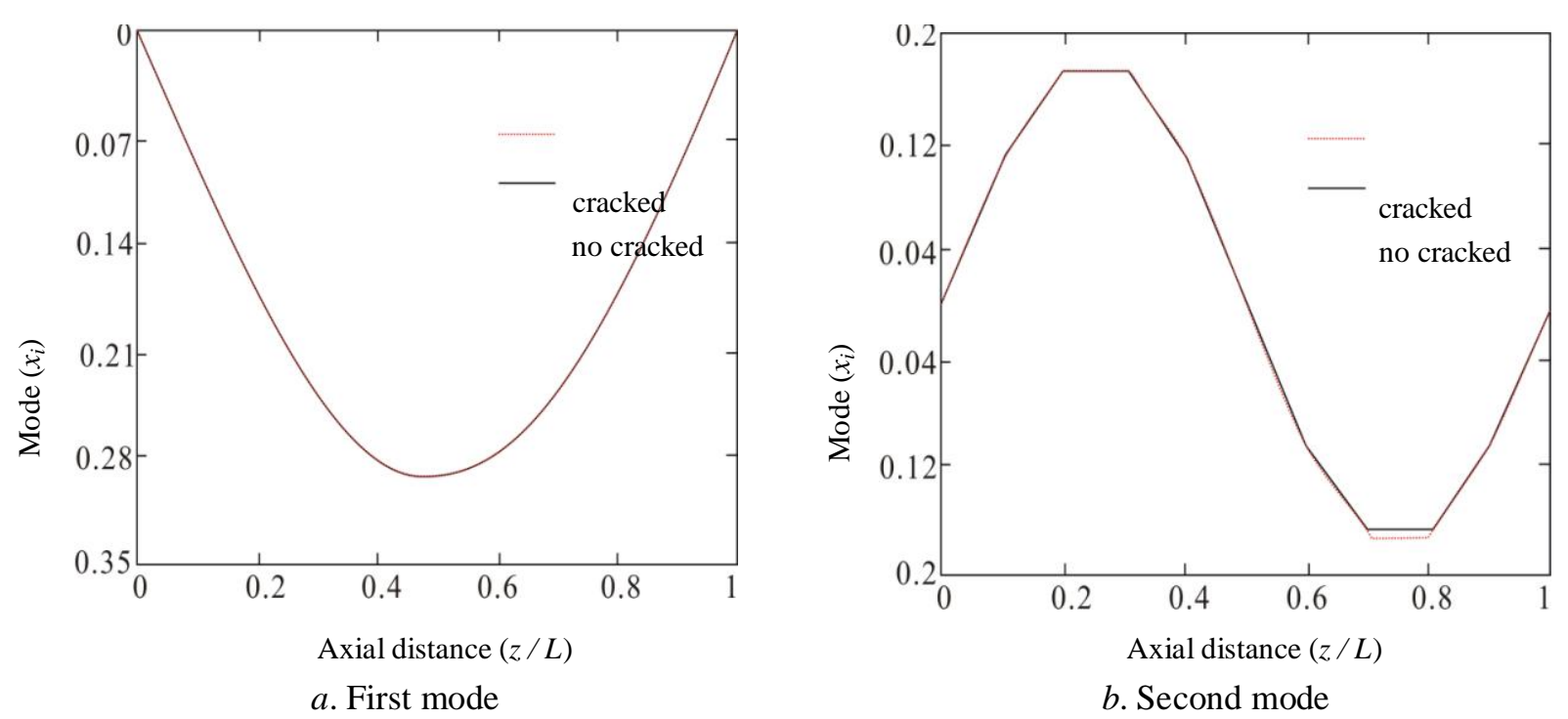

Fig.6 Modes of cracked and no cracked shafts (L / D=10)

\section{Influence of Crack Depth}

When $\mathrm{Z} 1 / \mathrm{L}=0.45, \mathrm{Z} 2 / \mathrm{L}=0.75, \bar{a}_{d 1}=a_{d 1} / R=0.5$ and change the relative depth of the second cracks $\bar{a}_{d 2}=a_{d 2} / R$, research the effect of crack depth on the vibration characteristics. Know the crack parameters. Calculate first three order characteristic frequency of the different slender ratio L / $\mathrm{D}$ with the change of second crack relative depth $\bar{a}_{d 2}=a_{d 2} / R$. See Fig.7. When the double crack position is known, the relative characteristic frequency of the shaft decreases obviously with the increase of relative crack depth. 


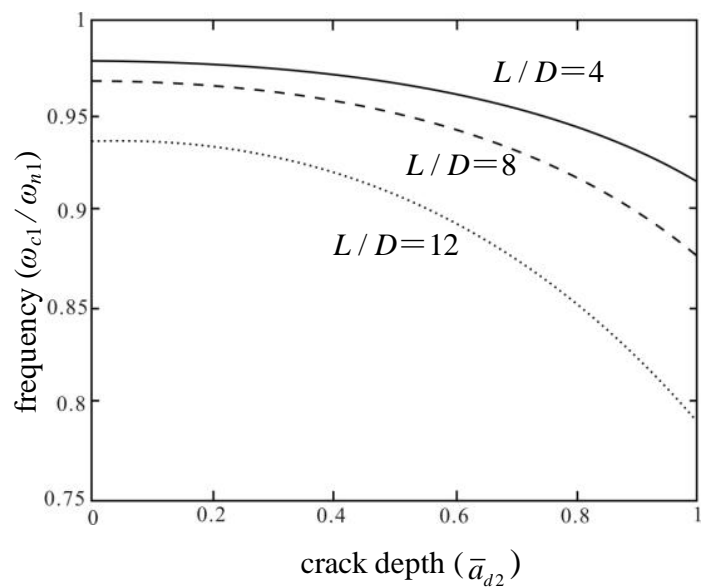

a. First characteristic frequency

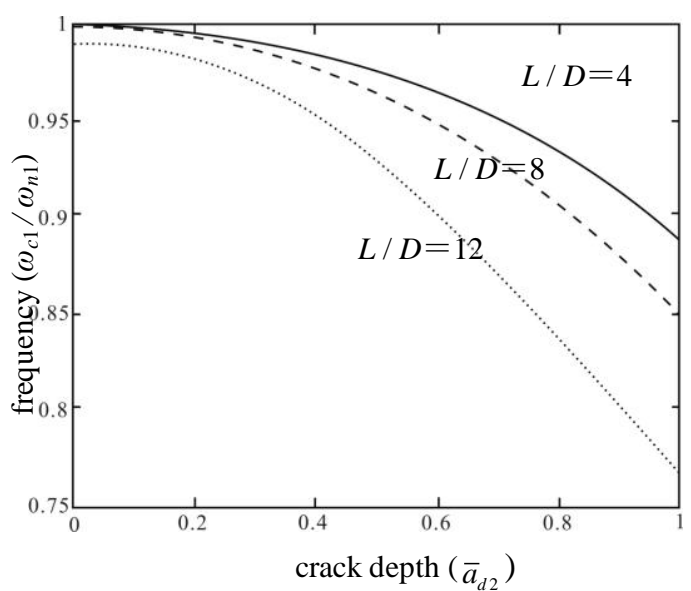

$b$. Second characteristic frequency

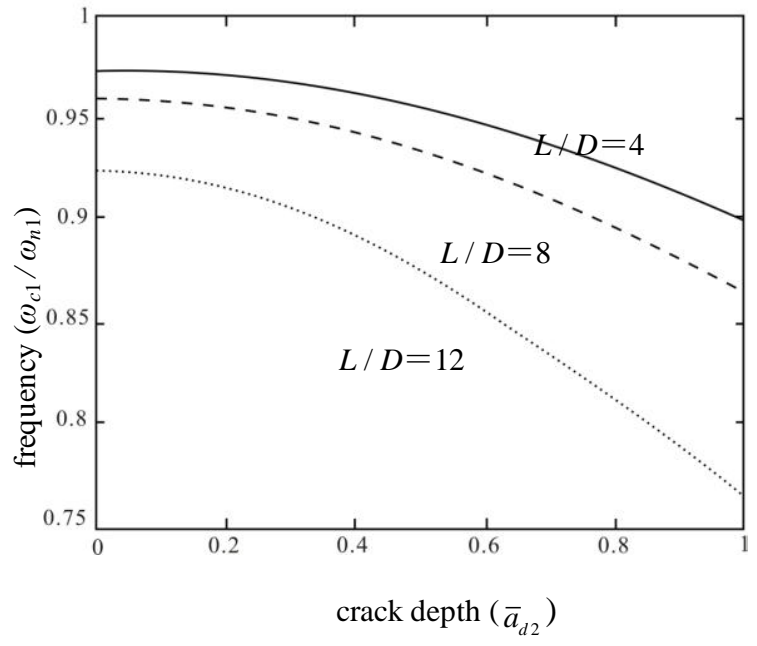

$c$ Third characteristic frequency

Fig.7 The influence of crack depth on the characteristic frequency

\section{Influence of Crack Location}

When $\mathrm{Z} 1 / \mathrm{L}=0.45, \bar{a}_{d 1}=0.5, \bar{a}_{d 2}=0.5$, and slender ratio $\mathrm{L} / \mathrm{D}=8$, research the $\mathrm{r}$ characteristic frequency of crack shaft with the change of crack location lc2 / 1. See Tab. 3. In the unit the characteristic frequency of the shaft with different crack position is different. When the crack is in the same unit, the difference of the characteristic frequency of the shaft can reach 1.66\%. See Fig.8. Under the same crack depth, the change of the characteristic frequency of the shaft depends on the distance between the crack and the specific mode node. If the crack is located in the vicinity of the anti node of a certain mode, the characteristic frequency will change greatly, and the characteristic frequency of the crack is smaller when the crack is located at the node of the mode.

Tab. 3 Relationship of characteristic frequency between different crack location

\begin{tabular}{|c|c|c|c|c|c|}
\hline & $l_{c 2} / l=1 / 6$ & $l_{c 2} / l=2 / 6$ & $l_{c 2} / l=3 / 6$ & $l_{c 2} / l=4 / 6$ & $l_{c 2} / l=5 / 6$ \\
\hline$\omega_{c 1} / \omega_{n 1}$ & 0.9482 & 0.9499 & 0.9515 & 0.9531 & 0.9546 \\
\hline$\omega_{c 2} / \omega_{n 2}$ & 0.9668 & 0.9637 & 0.9636 & 0.9634 & 0.9633 \\
\hline$\omega_{c 3} / \omega_{n 3}$ & 0.9681 & 0.9648 & 0.9610 & 0.9566 & 0.9515 \\
\hline
\end{tabular}




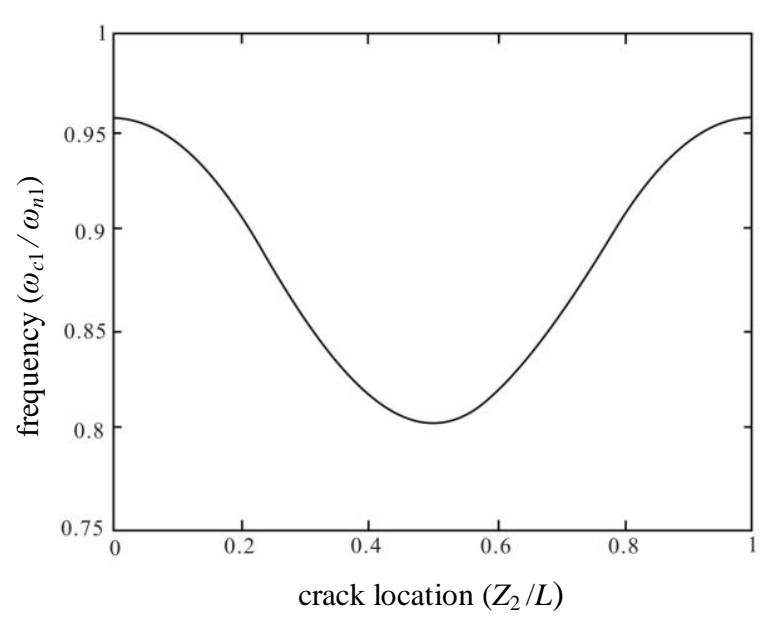

$a$. First characteristic frequency

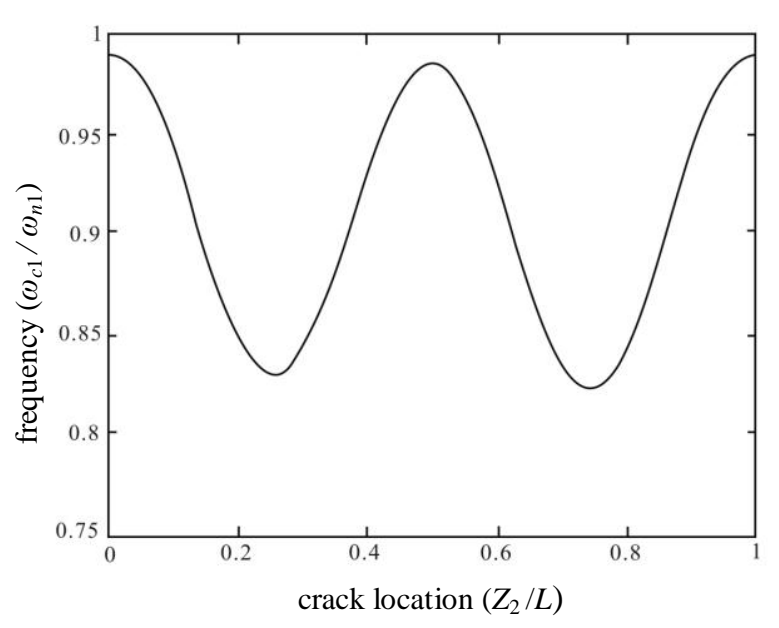

$b$. Second characteristic frequency

Fig. 8 Relationship of characteristic frequency between different crack location $(L / D=8)$

\section{Summary}

The analytical calculation of the shaft vibration differential equation is complicated. In this paper, the numerical method is used to analyze the effect of the crack on the vibration of shaft. Firstly, use CAE finite element software Patran/Nastran to calculate and compare the free shaft mode and the crack shaft mode. The crack has a certain influence for the local vibration (displacement) of shaft, and the natural frequency of shaft change. By the simplified finite element model based on the transfer matrix, the natural frequencies and modes of the shaft at different length and crack depth and crack location are numerically calculated. When the crack appears, the vibration of less slender ratio shaft changes more than another shaft. The characteristic frequency of the shaft decreases obviously with the increase of the relative depth of crack. The crack near the anti node in a mode of the order characteristic frequency is changed greatly. Otherwise when the node near the crack in the characteristic frequency mode changes small.

\section{Reference}

[1] Wen Bangchun et al. Advanced rotor dynamics, Beijing: China Machine Press. 2000.

[2] Zhang Wen. Theoretical basis of rotor dynamics. Beijing: Science Press, 1990.

[3] Zhong Yie et al. Rotor dynamics. Beijing: Tsinghua University press, 1987.

[4] Tsai TC, Wang YZ. The vibration of a multi-crack rotor. International Journal of Mechanical Sciences, 1997, 39(9), 1037-1053.

[5] Tsai TC, Wang YZ. Vibration analysis and diagnosis of a cracked shaft. Journal of Sound and Vibration, 1996, 192(3), 607-620. 